\title{
The Influence of Survival Analysis on Runx3 Gene Expression in the Primary Tumor of Patients Suffering from Stomach Carcinoma
}

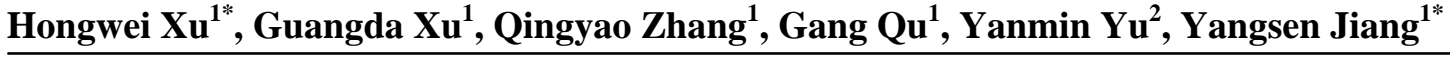 \\ ${ }^{1}$ Department of General Surgery and Minimally Invasive Gastrointestinal Surgery, Xinhua Hospital, Dalian University, Dalian, China; \\ ${ }^{2}$ Huangpu Central Hospital of Shanghai, Shanghai, China. \\ Email: xuhongwei@ymail.com
}

Received October $16^{\text {th }}, 2012$; revised November $18^{\text {th }}, 2012$; accepted November $27^{\text {th }}, 2012$

\begin{abstract}
Background: Runt domain transcription factor 3 (Runx3) is a putative tumor suppressor in human neoplasia. Previous researches suggested that a lack of Runx3 function contributed to human gastric carcinogenesis, however, it is not clear whether Runx3 is closely associated with clinicopathological features of primary stomach tumor and survival rate of patients. Aims: The article is to investigate the influence of survival analysis on Runx3 gene expression in the primary stomach tumor. Methods: Runx3 mRNA expression was detected in 108 primary gastric tumors and non-tumor tissue by semiquantitative reverse transcription-PCR (RT-PCR). All patients were followed up more than five years after radical gastrectomy. Results: There was a loss or substantial decrease of Runx3 mRNA expression in 108 cases of gastric tumors as compared with that in normal gastric mucosa $(\mathrm{p}<0.001)$. According to the gray scale median of Runx3 mRNA in primary tumors, the 108 cases were separated into two groups: The lower expressing group $(\leq 0.403)$ and the over one $(>0.403)$. By comparing analysis of clinical information between two groups, it was found that the lower expression of Runx3 mRNA in the primary tumor was not only associated with the poor clinicopathological factors, but also the inferior survival duration and cumulative survival rate of patients $(\mathrm{p}<0.05)$. Conclusions: These results strongly suggest that Runx3 was an independent prognostic factor and a potential therapeutic target for gastric cancer.
\end{abstract}

Keywords: Stomach Neoplasms; Runx3; Prognosis

\section{Introduction}

Gastric cancer is one of the most common malignancies, with an extremely poor prognosis, and is the second leading cause of cancer death worldwide [1]. The prevalence of gastric cancer in China is among the highest in the world, along with Japan and Korea. Despite advances in its diagnosis and treatment, the prognosis for advanced gastric cancer is still poor, with a five-year survival rate less than $10 \%$ [2]. By the time the patient is clinically diagnosed, the gastric cancer has often grown beyond the limits of curative resection. This reality has raised therapeutic problems, and new early diagnostic tools, therapeutic techniques and prognosis concerning this disease is urgently needed.

Runt domain transcription factors (Runxs) are homologous to products encoded by the Drosophila segmentation genes runt and lozenge. The Runx gene family consists of three members, Runx1/AML1, Runx2, and

${ }^{*}$ Corresponding authors.
Runx3 [3]. All three Runx family members play important roles in normal developmental processes and in carcinogenesis [3-5]. The Runx3 gene is located on human chromosome $1 \mathrm{p} 36, \alpha$ region that has long been suspected to harbor one or more suppressors of various tumors [6]. Previous studies suggest that lack of Runx 3 function is causally related to the genesis and progression of human gastric cancer, indicating that Runx3 is a novel tumour suppressor [7]. Runx3 shows remarkable down-regulation in gastric cancers compared to the surrounding mucosa, and the percentage of down-regulation increases as the cancer stage progresses. Furthermore, Runx 3 expression is reduced in intestinal metaplasia, a precancerous state, compared with normal mucosa, suggesting that down-regulation of Runx3 occurs at the early stages of gastric carcinogenesis, and that loss of Runx 3 expression increases the potential for gastric carcinogenesis [7].

Whether Runx3 is a prognostic marker in gastric cancer is still unclear since to date no extensive study has been performed correlating Runx3 expression with cli- 
nicopathological features and prognosis. We performed an RT-PCR study to investigate the possible role of the expression of Runx3 gene in clinicopathology and prognosis. Our results suggest that there was not only a significant correlation of reduced Runx 3 mRNA expression in the primary tumor with the poor clinicopathological factors and prognosis of stomach carcinoma, but also the lower five-year survival rate and cumulative survival rate of patients suffering stomach cacinoma. It is suggested that Runx3 may play an important role in the evolution of gastric adenocarcinoma and should be considered as a potential marker for the prognosis.

This template, created in MS Word 2003 and saved as "Word 97-2003 \& 6.0/95-RTF" for the PC, provides authors with most of the formatting specifications needed for preparing electronic versions of their papers. All standard paper components have been specified for three reasons: 1) ease of use when formatting individual papers; 2) automatic compliance to electronic requirements that facilitate the concurrent or later production of electronic products; and 3) conformity of style throughout a journal paper. Margins, column widths, line spacing, and type styles are built-in; examples of the type styles are provided throughout this document and are identified in italic type, within parentheses, following the example. Some components, such as multi-leveled equations, graphics, and tables are not prescribed, although the various table text styles are provided. The formatter will need to create these components, incorporating the applicable criteria that follow.

\section{Materials and Methods}

\subsection{Tissue Samples}

In this study we enrolled 108 patients (74 males and 34 females; age range 28 - 90 years, median age $64 \pm 10.5$ ) who underwent surgery at the Tenth People's Hospital of Shanghai Tongji University, China during from December 2000 to December 2003. Tumor tissue and non-neoplastic tissue from all patients was collected from the resected specimen in the operating room within $30 \mathrm{~min}-$ utes after the removal of the stomach. Non-neoplastic tissue was removed from the normal gastric tissue at a distance of at least $5 \mathrm{~cm}$ from the tumor. Written informed consent was obtained from each patient before tissue acquisition and all patients had a record of clinicopathological parameters. The study was approved by the Ethics Committee of the Tenth People's Hospital of Shanghai in accordance with the current Chinese rules. Tissue sections from all gastric cancer cases were reviewed and confirmed by a pathologist. We excluded cases preoperatively treated with radiation and/or chemotherapy. All specimens were rapidly frozen in liquid nitrogen and stored at $-80^{\circ} \mathrm{C}$ until RNA extraction. All patients were followed up more than five years after radical gastrectomy until death or December 2009, whichever came first.

\subsection{RNA Extraction and Real-Time PCR for Runx3 mRNA}

Total RNAs were obtained from various gastric tissues including primary gastric cancer and corresponding nontumorous gastric mucosa by using the Trizol according to the manufacture's protocol (Invitrogen), cDNAs were synthesized from $1 \mu \mathrm{g}$ total RNA by random priming using a First-Strand cDNA Synthesis Kit (Amersham Biosciences, Buckinghamshire, United Kingdom). The reaction mixture was incubated for 10 minutes at $25^{\circ} \mathrm{C}$, then at $37^{\circ} \mathrm{C}$ for 120 minutes. cDNA was stored at $-80^{\circ} \mathrm{C}$ until use.

Runx 3 cDNA was amplified by PCR with the sense primer, Runx3 gene, sense 5'-ATGACGAGAACTACTCCGCT-3' and the antisense primer 5'-GGTCGGAGAATGGGTTCAGT-3'. As a control, $\beta$-actin cDNA was amplified using the sense 5'-GACGAGGCCCAGAGCAAGAGAGG-3' and the antisense primer (5'-GATCCACATCTGCTGGAAGGTGGAC-3'. Semiquantitative PCR amplification was carried out in a $10 \mu \mathrm{L}$ PCR mixture containing $2 \mu \mathrm{L}$ of the cDNA template and 0.1 $\mu \mathrm{L}$ of TaKaRa hotstart Taq polymerase, $0.2 \mathrm{mM}$ of deoxynucleotide triphosphates, $0.5 \mu \mathrm{M}$ of each primer (sense and antisense), $1 \mu \mathrm{L}$ of the primer $10 \times$ PCR buffer, and 5.6 $\mu \mathrm{L}$ of distilled water. The PCR mixture was amplified using GeneAmp PCR system 9600 (Perkin-Elmer, Wellesley, MA, USA). The PCR conditions were as follows: preheating at $95^{\circ} \mathrm{C}$ for 5 minutes followed by 35 cycles of denaturation for 30 seconds at $95^{\circ} \mathrm{C}$, annealing for 1 minute at $55^{\circ} \mathrm{C}$, and extension for 1 minute at $72^{\circ} \mathrm{C}$, with a final extension for 5 minutes at $72^{\circ} \mathrm{C}$. The PCR products were loaded onto a $2 \%$ agarose gel containing ethidium bromide and visualized under ultraviolet (UV) transillumination.

\subsection{All Patients Were Followed Up}

And all patients were followed up more than five years after radical gastrectomy. Patients were observed until death or end of follow-up (October 31, 2007), whichever came first. Ascertainment of deaths included reporting by the family. In rare patients who died as a result of gastric cancer not previously reported, we obtained medical records with permission from next of kin. More than $98 \%$ of deaths in the cohorts were identified by these methods.

\subsection{Statistical Analysis}

Statistical analysis was performed using Student's t-test, $\chi^{2}$-test or two-tailed Fisher's exact test. Continuous vari- 
ables were determined as the mean \pm standard deviation. Survival was analyzed by the Kaplan-Meier method, and differences in the distribution were evaluated using the log-rank test. Data analyses were performed using the SPSS for Windows (V.17.0, SPSS, Chicago, IL, USA), and $\mathrm{p}<0.05$ was considered as significant.

\section{Results}

\subsection{Expression of Runx3 in Gastric Adenocarcinoma}

RT-PCR detection of Runx3 expression in normal gastric mucosa and gastric carcinoma tissues are shown in Figure 1. Runx3 gene was expressed positively in $21.3 \%$ (23 out of 108) of gastric adenocarcinoma and 62.0\% (67 out of 108) of distal normal mucosa. Furthermore very strong band was identified for Runx3 in normal gastric mucosa, but more indefinite in the gastric cancer. The fragment in size is as same as to the design (i.e. $396 \mathrm{bp}$ ). The arithmetic mean on gray scale bands of Runx3 (Runx $3 / \beta$-anctin) in primary tumors was significantly lower than in non-tumorous gastric mucosa $(0.33 \pm 0.12$ versus $0.65 \pm 0.21, p<0.001$, Figure 2). According to the gray scale median $(0.403$, range from 0.068 to 1.211$)$ of Runx 3 mRNA in primary tumors, the 108 cases were separated into two groups: the lower expressing group $(\leq 0.403)$ and the over one $(>0.403)$.

Association between Runx3 expression and clinicopathologic characteristics of gastric carcinoma patients.

The associations between Runx3 expression in primary tumors and clinicopathologic features are shown in Table 1. With respect to the TNM tumor staging gastric adenocarcinoma with lower expression of Runx 3 was $55.5 \%$ (15 out of 27) at stages I and II, 77.8\% (63 out of 81 ) at stages III and IV, respectively, thus the associativity between the loss of Runx 3 mRNA expression in the primary tumor and the advanced clinical stage was statistically significant $(\mathrm{p}=0.026)$ (Table 1). Lower expression of Runx3 was significantly correlated with distant metastasis $(p=0.007)$, LN metastasis $(p=0.035)$, infiltrative depth $(\mathrm{p}=0.033)$, and histologic grade $(\mathrm{p}=$ 0.034 ), respectively. But no significant associations were seen with patient gender $(p=0.628)$, age $(p=0.633)$, or with the growth pattern $(p=0.791)$ of the tumour (Table 1).

\subsection{Survival Analysis}

The median overall survival (OS) for Runx3 mRNA higher expression $(>0.403)$ and lowed expression $(\leq$ 0.403 ) was 1345 and 909 days, respectively (log-rank

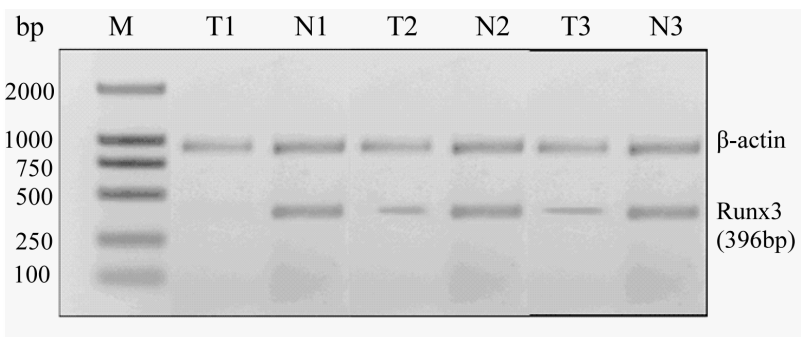

Figure 1. RT-PCR analyses of Runx3 mRNA expression in primary gastric cancer tissues and corresponding non-tumorous gastric mucosa. Weak or loss expression of Runx3 mRNA in the primary tumor (T). Positive for Runx3 mRNA expression in non-tumorous gastric mucosa $(\mathrm{N})$. Abbreviations: M, maker.

Runx3 mRNA

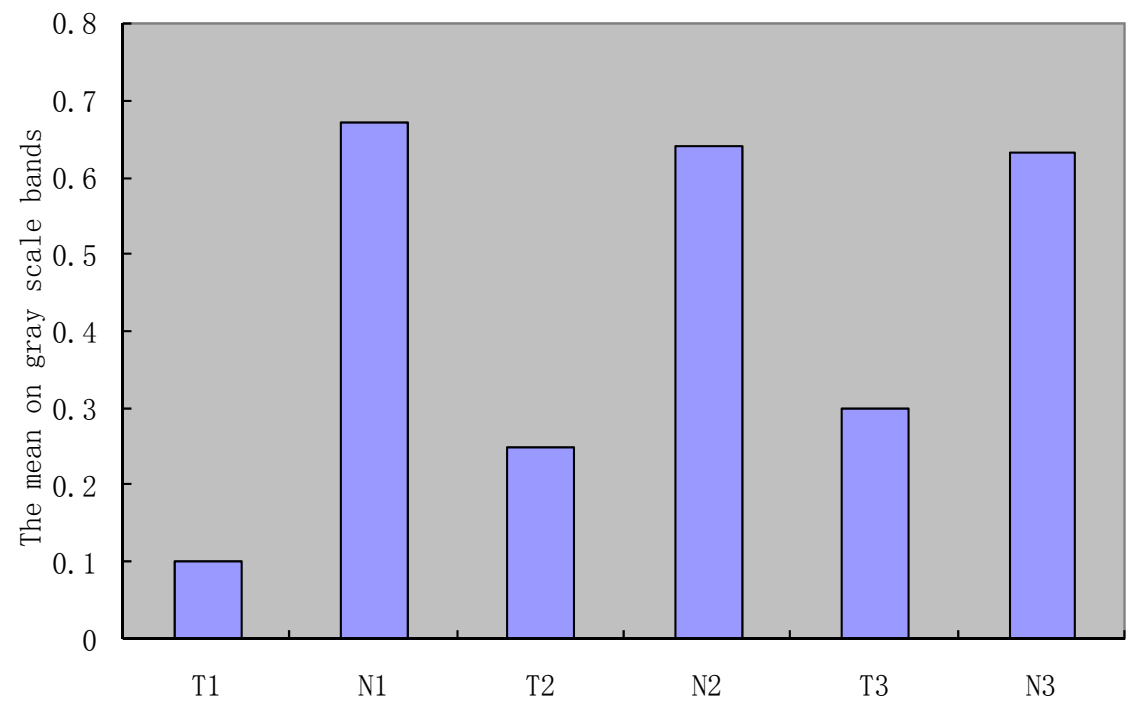

Figure 2. The arithmetic mean on gray scale bands of Runx3 mRNA in primary tumors and non-tumorous gastric mucosa (semiquantitative RT-PCR; T: the primary tumor; N: the non-tumorous gastric mucosa). 
Table 1. Associations between expression of Runx3 and clinicopathological features of gastric cancer.

\begin{tabular}{|c|c|c|c|c|}
\hline \multirow{2}{*}{ Cinicopathological Parameters } & \multirow{2}{*}{$\mathrm{n}$} & \multicolumn{2}{|c|}{ Runx3 mRNA expression $\mathrm{n}=108$} & \multirow{2}{*}{$\mathrm{p}$} \\
\hline & & $\leq 0.403$ & $>0.403$ & \\
\hline \multicolumn{5}{|l|}{ Sex } \\
\hline male & 73 & 41 & 32 & \multirow[t]{2}{*}{0.628} \\
\hline female & 35 & 19 & 16 & \\
\hline \multicolumn{5}{|l|}{ Age (years) } \\
\hline$<60$ & 49 & 28 & 21 & \multirow[t]{2}{*}{0.633} \\
\hline$\geq 60$ & 59 & 31 & 28 & \\
\hline \multicolumn{5}{|l|}{ Growth pattern } \\
\hline expansive & 42 & 24 & 18 & \multirow{2}{*}{0.791} \\
\hline Infiltrative & 66 & 36 & 30 & \\
\hline \multicolumn{5}{|l|}{ Histologic gradec } \\
\hline WD and MD pd & 59 & 45 & 14 & \multirow[t]{2}{*}{0.034} \\
\hline $\mathrm{PD}$ & 49 & 28 & 21 & \\
\hline \multicolumn{5}{|l|}{ Infiltrative depth } \\
\hline $\mathrm{T} 1+\mathrm{T} 2$ & 47 & 32 & 15 & \multirow[t]{2}{*}{0.033} \\
\hline $\mathrm{T} 3+\mathrm{T} 4$ & 61 & 52 & 9 & \\
\hline \multicolumn{5}{|l|}{ LN metastasis } \\
\hline Absence & 34 & 18 & 16 & \multirow[t]{2}{*}{0.035} \\
\hline Presence & 74 & 54 & 20 & \\
\hline \multicolumn{5}{|l|}{ Distant metastasis } \\
\hline Absence & 77 & 64 & 13 & \multirow[t]{2}{*}{0.007} \\
\hline Presence & 31 & 18 & 13 & \\
\hline \multicolumn{5}{|l|}{ TNM stage } \\
\hline I and II & 27 & 15 & 12 & \multirow[t]{2}{*}{0.026} \\
\hline III and IV & 81 & 63 & 18 & \\
\hline
\end{tabular}

Abbreviations: LN: lymph node; WD: well differentiated; MD: moderately differentiated; PD: poorly differentiated.

test $p=0.000$, Figure 3 ). By comparing analysis of clinical information between two groups with two-tailed Fisher's exact test or Kaplan-Meier method, it was found that, the loss of Runx 3 mRNA expression in the primary tumor was not only associated with the poor clinicopathological factors, but also the lower five-year survival rate and overall survival rate of patients suffering stomach carcinoma $(p<0.05)$. Follow-up data showed that a significantly decreasing trend in 5-year survival was observed in primary tumors patients with the lower expression of Runx3 (from 25\% of the higher one to 13\% of the lower one, $\mathrm{p}<0.005)$.

\section{Discussion}

The aggressive nature of human metastatic gastric carcinoma is related to genetic instability, reactivation of telomerase, mutations of various oncogenes and tumor suppressor genes [8] and abnormalities in several growth factors and their receptors. But no single factor that ac- counts for the majority of cases has been identified [9]. These abnormalities affect the downstream signal transduction pathways involved in the control of cell growth and differentiation. Specifically, they confer a tremendous survival and development and progression to gastric cancer.

The Runt domain transcription factors 3 have been reported to play key roles in developmental pathways in various types of cancers [3-5]. Both human and animal studies in vivo and in vitro had indicated that Runx 3 is closely related to gastric carcinoma. Silencing of the Runx3 gene may induce many epithelial malignancies, including gastric cancer [10-12]. Enhanced expression of Runx3 has been demonstrated to inhibit gastric carcinoma cell growth in vitro, as well as tumorigenicity and metastasis. Moreover, Runx 3 is inactivated in more than $60 \%$ of human gastric cancers and various human gastric cancer cell lines have decreased Runx 3 expression [12, 13]. Li et al. found that Runx 3 expression was reduced in 


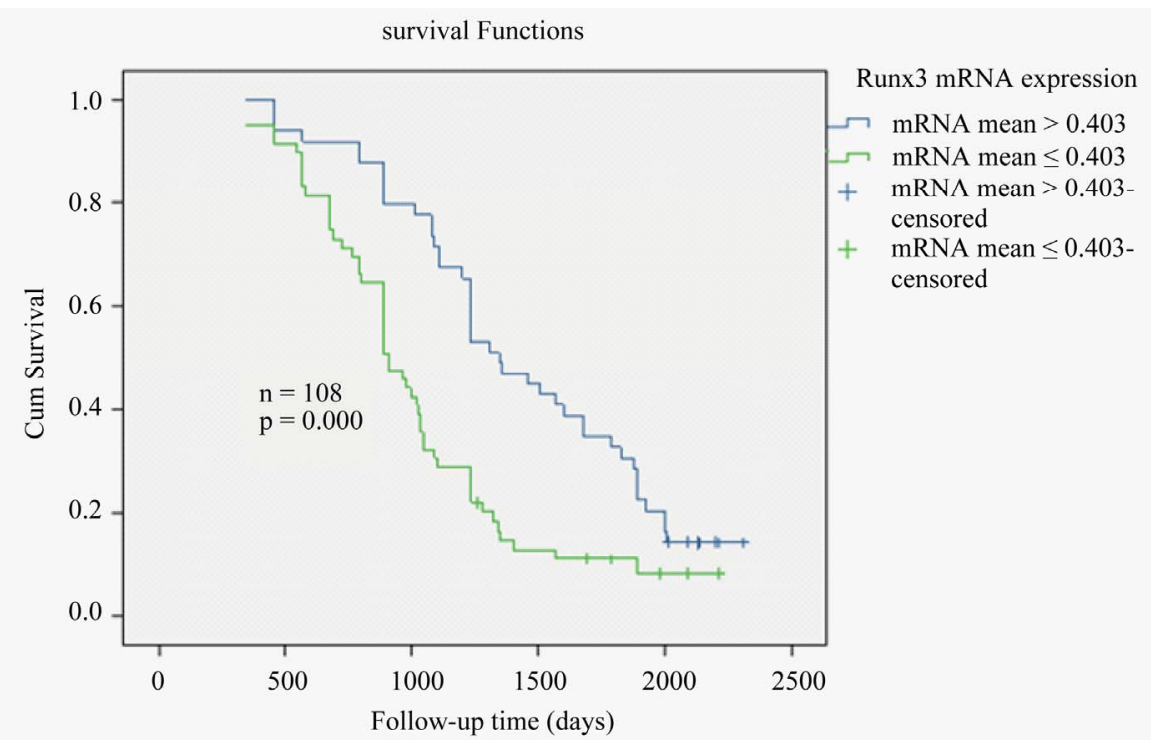

Figure 3. Kaplan-Meier survival analysis for gastric cancer patients according to the expression of Runx3. The y-axis represents the percentage of patients; the $x$-axis, their survival in days. The green line represents Runx3 mRNA lower expression in gastric carcinoma patients with a trend of worse survival than the blue line representing Runx3 mRNA higher expression in gastric carcinoma patients (Log-rank test: $p=0.000$ ). Mean survival times were 909 days for the Runx3 mRNA lower expression group and 1345 days for the Runx3 mRNA higher expression group.

$40 \%$ of early stage carcinomas, and the level increased to nearly $90 \%$ with the advancement of the cancer stage [12]. Wei et al. found that loss of Runx3 expression significantly affected the clinical outcome of gastric cancer patients [13]. Even though accumulating data suggests that Runx3 may also be a potential tumor suppressor in several tumors including gastric cancer $[12,14,15]$, systematic study about its association with clinicopathological features of primary stomach tumor and survival rate of patients are still lacking.

In this study, RT-PCR was used to confirm the expression level of Runx3 mRNA in paired samples of primary gastric cancer and non-tumorous tissue, and research data has shown that expression of the Runx3 gene was more frequently in the non-tumorous gastric mucosa than in the primary gastric cancer, suggesting the involvement of the tumor suppressor gene Runx3 in the pathogenesis of gastric carcinoma. Specifically, we found that the loss of Runx3 mRNA expression in the primary tumor was not only associated with the poor clinicopathological factors such as deep infiltration, distant organ metastasis, poorly differentiation, lymph metastasis and later clinicopathological stages, etc, but also the lower five-year survival rate and cumulative survival rate of patients suffering stomach carcinoma. The prognosis data showed that the decrease or loss of Runx 3 expression was inversely correlated with survival and could be an independent predictor of poor patient outcome.

Recently, studies have reported that silencing a tumor suppressor gene may result in loss of its function in tu- morigenesis [16]. Inactivation mechanisms of the Runx3 gene are believed to be promoter hypermethylation and homozygous deletion [16,17]. Genetic variants of the Runx3 gene may also play an inactivation role. For example, Kim et al. [17]. demonstrated Runx3 methylation in $8.1 \%$ of chronic gastritis specimens, $28.1 \%$ of intestinal metaplasia specimens, $27.3 \%$ of gastric adenoma specimens and $64 \%$ of gastric carcinoma specimens, suggesting increase of Runx3 methylation with progression of the lesion along the path of multistep gastric carcinogenesis. Li et al. found that the Runx3 Arg122Cys mutation within the Runx3 conserved Runt domain could affect the tumorsuppressive activity of Runx3 [12]. Also, Kim et al. examined mutations in the Runx3 coding regions in 34 bladder tumors and found missense mutations and single nucleotide deletion in the conserved Runt domain that abolished the DNA-binding ability of Runx3 and resulted in truncation of the protein [18]. This evidence generated the hypothesis that Runx3 genetic variants may affect the functions of Runx 3 , and consequently modulate the cell growth and apoptosis capacity of TGF- $\beta$, and participate in the etiology of human cancers [19].

In conclusion, we have examined the expression of Runx3 mRNA in human gastric cancer and its prognostic significance. This study has shown for several strengths that 1) a low proportion of gastric carcinomas expressed Runx3 and low expression of Runx3 was significantly associated with unfavorable clinicopathologic variables such as low clinical stage (stages III and IV), lymph node 
metastasis, histologic grade and distant metastasis, however, there are a few different with previous studies. The reasons for this result may be caused by the long-term prognosis of patients with gastric cancer is influenced by not only Runx3 but also other factors such as patient's performance, tumor stage, ethnic differences, and the performance of gastrectomy; and 2) it is the first study to investigated the association between the Runx 3 mRNA expression and survival rate in the primary tumor of patients suffering from stomach carcinoma, and low expression of Runx 3 was associated with a significantly shorter survival in gastric carcinoma patients. Taken together, our findings indicate that Runx 3 may be involved in the progression of gastric carcinomas and are significant prognostic indicators for gastric carcinoma patients.

\section{Acknowledgements}

This study was supported by the National Natural Science Foundation of China, No. 30171039; Our work was finished in Shanghai Institute of Endocrine and Metabolic Diseases, Rui-Jin Hospital, Shanghai Jiao Tong University School of Medicine, China and thank Dr. Xiaoying Li for the kind help.

\section{REFERENCES}

[1] F. Pasini, A. P. Fraccon and G. D. E. Manzoni, "The Role of Chemotherapy in Metastatic Gastric Cancer," Anticancer Research, Vol. 31, No. 10, 2011, pp. 3543-3554.

[2] V. Catalano, R. Labianca, G. D. Beretta, G. Gatta, F. de Braud and E. Van Cutsem, "Gastric Cancer," Critical Reviews in Oncology/Hematology, Vol. 71, No. 2, 2009, pp. 127-164. doi:10.1016/j.critrevonc.2009.01.004

[3] Y. Ito, "Oncogenic Potential of the Runx Gene Family: 'Overview',' Oncogene, Vol. 23, No. 24, 2004, pp. 41984208. doi:10.1038/sj.onc. 1207755

[4] S. C. Bae and J. K. Choi, "Tumor Suppressor Activity of Runx3," Oncogene, Vol. 23, No. 24, 2004, pp. 4336-4340. doi:10.1038/sj.onc. 1207286

[5] K. Blyth, E. R. Cameron and J. C. Neil, "The Runx Genes: Gain or Loss of Function in Cancer," Nature Reviews Cancer, Vol. 5, No. 5, 2005, pp. 376-387. doi:10.1038/nrc1607

[6] Y. Ito, "Runx Genes in Development and Cancer: Regulation of Viral Gene Expression and the Discovery of Runx Family Genes," Advances in Cancer Research, Vol. 99, 2008, pp. 33-76. doi:10.1016/S0065-230X(07)99002-8

[7] Y. Nakase, C. Sakakura, K. Miyagawa, et al., "Frequent Loss of Runx3 Gene Expression in Remnant Stomach Cancer and Adjacent Mucosa with Special Reference to Topography," British Journal of Cancer, Vol. 92, No. 3, 2008, pp. 562-569.

[8] B. G. Jang and W. H. Kim, "Molecular Pathology of Gastric Carcinoma," Pathobiology, Vol. 78, No. 6, 2011, pp. 302-310. doi:10.1159/000321703

[9] J. P. Hamilton' and S. J. Meltzer, "A Review of the Genomics of Gastric Cancer," Clinical Gastroenterology and Hepatology, Vol. 4, No. 4, 2006, pp. 416-425. doi:10.1016/j.cgh.2006.01.019

[10] H. Shiraha, S. Nishina and K. Yamamoto, "Loss of RuntRelated Transcription Factor 3 Causes Development and Progression of Hepatocellular Carcinoma," Journal of Cellular Biochemistry, Vol. 112, No. 3, 2011, pp. 745749. doi:10.1002/jcb. 22973

[11] N. Yanagawa, G. Tamura, H. Oizumi, et al., "Promoter Hypermethylation of RASSF1A and Runx3 Genes as an Independent Prognostic Prediction Marker in Surgically Resected Non-Small Cell Lung Cancers," Lung Cancer, Vol. 58, No. 1, 2007, pp. 131-138. doi:10.1016/j.lungcan.2007.05.011

[12] E. J. Kim, Y. J. Kim, P. Jeong, Y. S. Ha, S. C. Bae and W. J. Kim, "Methylation of the Runx3 Promoter as a Potential Prognostic Marker for Bladder Tumor," Journal of Urology, Vol. 180, No. 3, 2008, pp. 1141-1145. doi:10.1016/i.juro.2008.05.002

[13] D. Wei, W. Gong, S. C. Oh, et al., "Loss of Runx3 Expression Significantly Affects the Clinical Outcome of Gastric Cancer Patients and Its Restoration Causes Drastic Suppression of Tumor Growth and Metastasis," Cancer Research, Vol. 65, No. 11, 2005, pp. 4809-4816. doi:10.1158/0008-5472.CAN-04-3741

[14] Y. Tokumaru, S. Nomoto, C. Jeronimo, et al., "Biallelic Inactivation of the RIZ1 Gene in Human Gastric Cancer," Oncogene, Vol. 22, No. 44, 2003, pp. 6954-6958. doi: $10.1038 /$ sj.onc. 1206403

[15] A. Goel, C. N. Arnold, P. Tassone, et al., "Epigenetic Inactivation of Runx3 in Microsatellite Unstable Sporadic Colon Cancers," International Journal of Cancer, Vol. 112, No. 5, pp. 754-759. doi:10.1002/ijc.20472

[16] D. Levanon, Y. Bernstein, V. Negreanu, K. R. Bone, A. Pozner, R. Eilam, J. Lotem, O. Brenner and Y. Groner, "Absence of Runx3 Expression in Normal Gastrointestinal Epithelium Calls into Question Its Tumour Suppressor Function," EMBO Molecular Medicine, Vol. 3, No. 10, 2011, pp. 593-604. doi:10.1002/emmm.201100168

[17] T. Y. Kim, H. J. Lee, K. S. Hwang, et al., "Methylation of Runx3 in Various Types of Human Cancers and Premalignant Stages of Gastric Carcinoma," Laboratory Investigation, Vol. 84, No. 4, 2004, pp. 479-484. doi:10.1038/labinvest.3700060

[18] W. J. Kim, "Runx3 Inactivation by Point Mutations and Aberrant DNA Methylation in Bladder Tumors," Cancer Research, Vol. 65, No. 20, 2005, pp. 9347-9354. doi:10.1158/0008-5472.CAN-05-1647

[19] M. Suzuki, H. Suzuki, Y. Minegishi, K. Ito, T. Nishizawaand and T. Hibi, "H. Pylori-Eradication Therapy Increases Runx3 Expression in the Glandular Epithelial Cells in Enlarged-Fold Gastritis," Journal of Clinical Biochemistry and Nutrition, Vol. 46, No. 3, 2010, pp. 259-264. doi:10.3164/jcbn.09-127 